\title{
Prisoners' Dilemma in Duopoly (Super)games ${ }^{1}$
}

\author{
Luca Lambert ini \\ Dipartimento di Scienze E conomiche \\ Università degli Studi di Bologna \\ Strada Maggiore 45 \\ 40125 B ologna, Italy \\ fax 39-51-6402664 \\ e-mail lamberti@spbo.unibo.it \\ and \\ Institute of Economics \\ University of Copenhagen \\ Studiestræde 6 \\ 1455 Copenhagen K, Denmark \\ fax 45-35323000 \\ e-mail okoll@pc.ibt.dk
}

December 17, 1998

${ }^{1}$ A cknowledgements. I would like to thank an associate editor for helpful suggestions, as well as V incenzo Denicolò, Gianpaolo Rossini and the audience at a seminar in Lund and at the 1997 Royal Economic Society Conference, Stoke-on-Trent, for comments and discussion on a previous draft. The usual disclaimer applies. 


\begin{abstract}
A bstract
The choice between quantity and price in order to stabilize collusion is modeled here. It is shown that this relocates the prisoners' dilemma backwards, from the market stage to the stage where the market variable is chosen in order to sustain collusion, and where discount rates appear as the payoas. Likewise, a prisoners' dilemma arises also when both the market variable and the type of behavior (cooperative or non-cooperative) are simultaneously chosen.

J EL classi..cation: C 72, D43, L 13.

K eywords: meta-game, supergame, prisoners' dilemma.
\end{abstract}

List of symbols: ${ }^{\circledR} ;{ }^{\circledR} ;{ }^{\circ} ; p_{i} ; q_{i} ; ! ; b ; 1 / 4 ; \not b_{4} ;$ i : 


\section{Introduction}

The question how ..rms should play an oligopoly game has received a good deal of attention in the recent literature. On the one hand, when non-cooperative pro..t maximization is considered, one may ask whether ..rms prefer to set prices or quantities, and whether they move simultaneously or sequentially. On the other hand, if attention is turned to collusive pro..t maximization, is cartel behavior more likely to be sustained by price or quantity-setting ..rms? The ..rst two questions, concerned with one-shot oligopoly games, have been tackled by Singh and Vives [16] and Hamilton and Slutsky [8], respectively. On the basis of the former contribution, we may expect ..rms to set quantities rather than prices when goods are substitutes, and vice versa when goods are complements. ${ }^{1}$ From the latter paper, it emerges that a simultaneous equilibrium will be observed only if ..rms choose to ..x outputs. Summing up, what we seemingly know so far as to one-shot games is that they are likely to be played simultaneously in the quantity (respectively, price) space if goods are substitutes (complements). ${ }^{2}$

A nother direction followed by the existing literature on the B ertrand-Cournot debate is that of capacity constraints, and their consequences on the shape of market competition when duopolists set prices (Levitan and Shubik [11]; K reps and Scheinkman [9]; Osborne and Pitchik [14]; Davidson and Deneckere [4]). The results obtained by this approach can be summarized as follows. When both ..rms have enough capacity to serve the whole market, the standard B ertrand outcome obtains. Otherwise, with binding capacity constraints, the Cournot outcome emerges, notwithstanding ..rms' price-setting behavior.

How about supergames? We examine several contributions dealing with the problem of cartel stability in price or quantity supergames (Deneckere [5]; Majerus [12]; Rothschild [15]). The conclusions reached in these papers are rather contradictory, and allow for the general consideration that cartel stability is highly sensitive to both the functional form selected for market demand and the number of ..rms. One of these contributions is of particular interest here, that of Deneckere [5], who adopts a model which is a slightly simpli..ed version of Singh and Vives', and ..nds that, along most of the substitutability range, a quantitysetting cartel is more easily sustained than a price-setting cartel (the opposite obviously holds when goods are complements). Hence, again it appears that Cournot behavior should emerge as the most pro.table one. However, neither

\footnotetext{
${ }^{1}$ See Cheng [3] for a graphical description of Singh and Vives' analysis. Vives [17] and Okuguchi [13] deal with the relative ec ciency of Bertrand and Cournot behavior.

${ }^{2}$ T his can be easily ascertained evaluating the payoxs yielded by simultaneous and sequential moves in the two settings where ..rms optimize in the same variable and in the mixed setting where they optimize in dixerent variables (Boyer and Moreaux [2]; Denicolò and Lambertini [6]).
} 
Deneckere nor others take into account the possibility that ..rms choose to collude in heterogeneous variables. This amounts to saying that, while indeed quantity behavior appears to minimize the probability of defection by either ..rm from the cartel agreement in a wide parameter range, the fact that this is also suc cient to ensure that ..rms will actually collude in output levels is far from being obvious.

I shall analyse this issue by considering the choice of the strategic variable as the outcome of ..rm's behavior, be that cooperative or non-cooperative, in a framework where the usual repeated market game leads to a meta-game, which is not necessarily observable, whose object is precisely the selection of the most et cient way to play the market game. Alternatively, the model I am going to present below can be interpreted as an extended game in two stages à la Hamilton and Slutsky [8], where ..rms ..rst non-cooperatively declare their preferences over the variable to be selected for the downstream market stage, given that in the latter they aim at minimizing the probability that either of them defects from a cooperative agreement conceived to maximize joint pro..ts. This will establish that, while in the market game the prisoners' dilemma concerns the choice of the behavior (cooperative vs non-cooperative), given the variable(s) being set by the ..rms, in the meta-game where the ..rms aim at minimizing the probability of defection, the prisoners' dilemma shows up as involving the choice of the market variable (price vs quantity), given the cooperative attitude that ..rms are assumed to exhibit in the market game. Finally, I will show that a prisoners' dilemma also axects the game where ..rms choose at the same time between cooperating or not and between B ertrand or Cournot competition.

The remainder of the paper is structured as follows. In section 2 the basic model is introduced. Then, section 3 deals with the usual prisoners' dilemma arising from market competition, while the prisoners' dilemma axecting the attempt at stabilizing collusion is treated in section 4 . The possibility for ..rms to choose both the variable and the type of behavior at the same time is dealt with in section 5 . Finally, section 6 provides concluding comments.

\section{The basic model}

The framework adopted here is a simpli..ed version of Singh and Vives' [16]. Two ..rms, labelled as $\mathrm{i}$ and $\mathrm{j}$, oxer a single product each. The marginal cost of production is assumed to be constant and equal across ..rms. For the sake of simplicity, I normalize it to zero. The inverse demand function faced by ..rm i when both producers set output levels is

$$
p_{i}=1 ; \quad q_{i}{ }^{\circ} q_{j} ;
$$

where $\mathrm{j}^{\circ} \mathrm{j} 2[0 ; 1]$ denotes the degree of substitutability between the two products, which are substitutes if ${ }^{\circ} 2$ 2]0; 1]; and complements if ${ }^{\circ} 2$ [i 1;0[: Given the nature of the model, in the remainder of the paper I will restrict attention to the 
case of substitutes. The direct demand function faced by ..rm i when both are price-setters is

$$
q_{i}=\frac{1}{1+{ }^{\circ}} i \frac{1}{1 i^{\circ 2}} p_{i}+\frac{\circ}{1 i^{\circ 2}} p_{j}:
$$

When instead ..rm i acts as a quantity-setter while ..rm j is a price-setter, their respective demand functions are

$$
\begin{gathered}
p_{i}=1 ; q_{i}+{ }^{\circ}\left(p_{j}+{ }^{\circ} q_{i} \text { i } 1\right) ; \\
q_{j}=1 ; p_{j} i{ }^{\circ} q_{i}:
\end{gathered}
$$

In the absence of production costs, each ...rm's pro..t function corresponds to revenue, $1 / 4=p_{i} q_{i}$ :

\section{Prisoners' dilemma in the market game}

As is well known, duopoly games, whether in prices or in quantities, are axected by a prisoners' dilemma, since for every ..rm the non-cooperative strategy dominates the cooperative one. The solution is provided by the folk theorem, which I shall adopt here in the usual "grim strategy" version (Friedman [7]), where deviation in one period triggers a Nash punishment forever, ${ }^{3}$ as in Deneckere [5], who obtained the following discount factors:

$$
\mathbb{\circledR}^{\mathrm{qq}}=\frac{\left({ }^{\circ}+2\right)^{2}}{{ }^{\circ}+8^{\circ}+8} ; \AA^{\mathrm{pp}}=\frac{\left({ }^{\circ} \mathrm{i} 2\right)^{2}}{0^{2} \mathrm{i} 8^{\circ}+8} ;{ }^{\circ} \cdot 0: 73 ;
$$

where superscript qq (respectively, pp) indicates that both ..rms set quantities (resp., prices). The constraint on ${ }^{\circ}$ is meant to guarantee the non-negativity of quantities in all phases. ${ }^{4}$ Provided ${ }^{\circledR q q}<{ }^{\circledR p p}$; Cournot behavior appears to ensure a greater stability of the cartel agreement than Bertrand behavior does. The reason can be found in the greater incentive to deviate that characterizes a cartel in prices.

I turn now to a brief description of the game where ..rms optimize in heterogeneous variables. The demand functions are (3) and (4). Straightforward computations yield the following Nash equilibrium pro..ts:

\footnotetext{
${ }^{3}$ Friedman's retaliation scheme is not the only one we could use. Optimal punishment schemes have been proposed in recent literature (see A breu [1]; and Lambson [10]). I adopt Friedman's formulation for the sake of comparison with the contributions referenced to in the text.

${ }^{4}$ If ${ }^{\circ} 2$ ] $\left.0: 73 ; 1\right]$; i.e., goods are very close substitutes, the non-negativity constraint on quantities yields a dixerent expression for ${ }^{\mathrm{pp} p}$ (see Deneckere [5, p. 41]). For the purposes of this paper, (5) suф ces.
} 


$$
1 / 4^{N}=\frac{\left({ }^{\circ} i 2\right)^{2}\left(1 i^{\circ 2}\right)}{\left(3^{\circ 2} i 4\right)^{2}} ; 1 / /^{\mathbb{N}}=\frac{\left({ }^{\circ} i 1\right)^{2}\left({ }^{\circ}+2\right)^{2}}{\left(3^{\circ} i_{4}\right)^{2}}
$$

where ..rm $\mathrm{i}$ is a quantity-setter, while ..rm $\mathrm{j}$ is a price-setter. The maximization of joint pro.ts requires $q_{i}^{M}=1=\left(2\left(1+{ }^{\circ}\right)\right)$ and $p_{j}^{M}=1=2$ : This pair of strategies yields cartel pro..ts : ${ }^{M}=1=\left(2\left(1+{ }^{\circ}\right)\right)$ : As to the pro.ts each ..rm gains under collusion, two possibilities arise. The ..rst is that both ..rms are entitled to half the cartel pro..ts (which is indeed the amount each of them obtains by substituting $q_{i}^{M}$ and $p_{j}^{M}=1=2$ into the individual pro..t functions), i.e., $1 / 4^{\mathrm{MM}}=1 / 4^{\mathrm{M}}=1^{\mathrm{M}}=2$; the second consists in splitting evenly the additional pro.ts made available by collusion, in the light of the asymmetry between non-cooperative pro..ts:

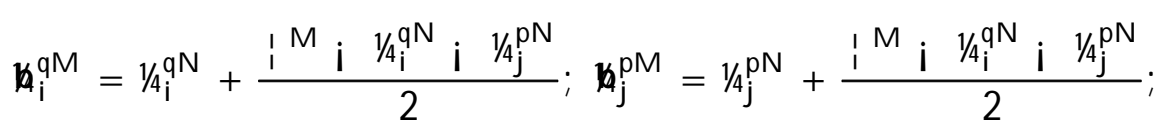

where obviously

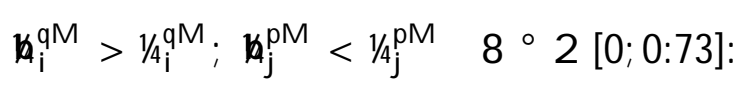

As to the deviation phase, the individually optimal deviation output (price) when the other ..rm sticks to the collusive price (output) corresponds to $\mathrm{q}_{\mathrm{P}}^{\mathrm{D}}=$ $\left(2 i^{\circ}\right)=\left(4\left(1 i^{\circ}\right)\right)$ and $p_{j}^{D}=\left(2+{ }^{\circ}\right)=\left(4\left(1+{ }^{\circ}\right)\right)$, respectively, yielding the following deviation pro..ts:

$$
1 / 4^{\mathrm{DD}}=\frac{\left({ }^{\circ} \mathrm{i} 2\right)^{2}}{16\left(1 \mathrm{i}^{\circ 2}\right)} ; 1 / 4^{\mathrm{DD}}=\frac{\left({ }^{0}+2\right)^{2}}{16\left(1+{ }^{\circ}\right)}
$$

and the following pro..ts for the ..rm being cheated:

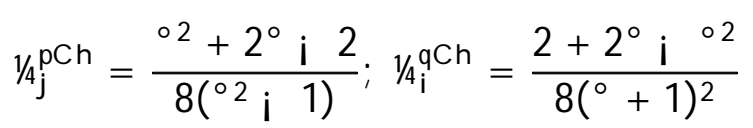

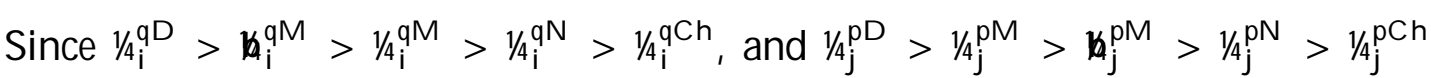
hold for the quantity-setter and the price-setter, respectively, the mixed situation where ..rms optimize in dixerent variables reproduces the prisoners' dilemma, irrespectively of the rule adopted to split cartel pro.ts. The question arises whether the quantity setter may be willing to give up part of the pro..ts she would obtain under (7) to allow the pricesetter to get half the monopoly pro..ts. An answer will be provided at the end of section 4. As in the pure price or quantity games, a Pareto-improvement on the non-cooperative outcome can be reached in the repeated game over an in..nite horizon, if ..rms $i$ and $j$ 's discount factors are at least as high as the critical thresholds, de..ned as:

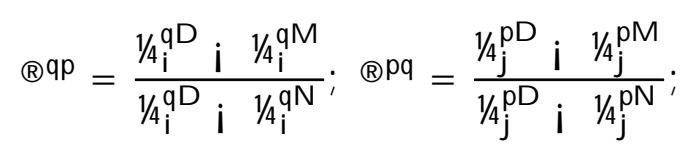


where superscript $\mathrm{qp}(\mathrm{pq})$ indicates that the discount factor is computed for the quantity-setter (price-setter), and $1 / 4^{\mathrm{M}}=1 / 4^{\mathrm{pM}}=1^{\mathrm{M}}=2$ : A Iternatively, if rule (7) is adopted,

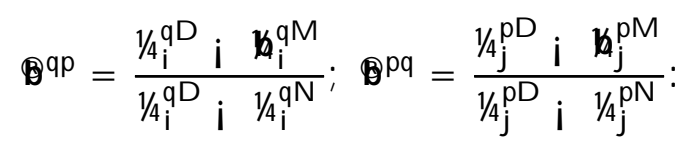

After some simple albeit tedious calculations, one ..nds that the individual discount factors must satisfy the following inequalities:

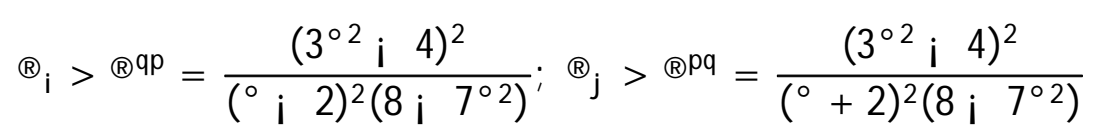

if cartel pro..ts are evenly split between the two ..rms, or

$$
\begin{aligned}
& \Theta_{1}>\mathbb{Q}^{\mathrm{qp}}=\frac{16 i 16^{\circ} i 8^{\circ 2}+16^{\circ 3} i 7^{\circ 4}}{\left({ }^{\circ} i 2\right)^{2}\left(8 ; 7^{\circ 2}\right)} ; \\
& \mathbb{B}_{3}>\mathrm{B}^{\mathrm{pq}}=\frac{16+16^{\circ} \mathrm{i} 8^{\circ 2} \text { i } 16^{\circ 3} \text { i } 7^{\circ 4}}{\left({ }^{\circ}+2\right)^{2}\left(8 ; 7^{\circ 2}\right)}
\end{aligned}
$$

if cartel pro..ts are split according to (7). These two pairs of critical discount factors can coexist when ${ }^{\circ} \cdot 0: 73$ :

\section{Prisoners' dilemma in the upstream stage}

The existing literature establishes that if ..rms selling substitute goods can choose between setting price or quantity, they end up with a Cournot-Nash outcome, since setting the output is a strictly dominant strategy (Singh and Vives [16]). They can seemingly proceed to an analogous choice in order to stabilize collusion (or minimize the probability of defection from the cartel agreement). To this aim, they must non-cooperatively choose to set prices or quantities so as to minimize their respective critical discount factors. The mechanism can be imagined to work as follows. In each period, ..rms face two overlapping problems. The ..rst is the usual market competition, which I have analysed in the previous section. If ..rms want to improve on the non-cooperative outcome, they must be patient enough to sustain collusion. The second consists in choosing the variable for the game, provided they are indeed aiming at stabilizing the cooperative agreement over time. The issue can also be approached by another route, by noting that, once they collude, the variable in which they are cooperating is in fact unobservable, ${ }^{5}$ so that they may wonder (i) which kind of deviation is more pro.table; and (ii) which kind of punishment is more severe, i.e., more likely to ensure stability.

\footnotetext{
${ }^{5} \mathrm{~W}$ ith the unique exception of the mixed case where they adopt rule (7).
} 
Summing up, from the repetition of the downstream stage in..nitely many times, ..rms obtain the critical discount factors pertaining to the symmetric market games where both set prices or quantities, and the asymmetric games where one sets the price and the other ..xes the output level. Proceeding backwards, ..rms non-cooperatively choose the strategic variable in the upstream stage, whose outcomes are de. ned in terms of the discount factors themselves.

The outcome of such a process, which follows purely from logical considerations and is not necessarily observable, is summarized in the following

Proposition 1 Due to the prisoners' dilemma which arises in the upstream phase of the repeated game, ..rms will choose to be price-setters instead of quantitysetters, even though Cournot behavior would ensure a higher degree of stability to the cartel agreement.

Proof. The normal form of the upstream stage of the game is described by matrix 1.

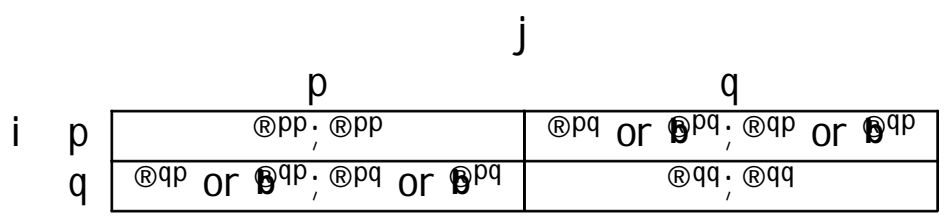

Matrix 1

Provided that, for ${ }^{\circ} \cdot 0: 73$

$$
\mathbb{\circledR}^{\mathrm{qp}}>\mathbb{\circledR}^{\mathrm{qp}}>\mathbb{\circledR}^{\mathrm{pp}}>\mathbb{\circledR}^{\mathrm{qq}}>\mathbb{}^{\mathrm{pq}}>\mathbb{\circledR}^{\mathrm{pq}} \text {; }
$$

and the game yields a prisoners' dilemma regardless of the rule adopted to split cartel pro..ts, in that the pair $(q ; q)$ leads to an outcome that Pareto-dominates the one associated with the pair $(p ; p)$, but players non-cooperatively select $(p ; p)$ as the Nash equilibrium strategy pair, since $p$ strictly dominates $q$.

Hence, when ..rms aim at sustaining collusion over time, they end up selecting the market variable which ensures an inet cient outcome. This highlights that the approach adopted in previous works in this ..eld, consisting in a straightforward comparison between $\mathbb{\circledR}^{\mathfrak{p p}}$ and $\mathbb{\circledR}^{q q}$, was largely misleading in that it didn't take into account any strategic consideration, namely, the fact that, given the other .rm's choice, a quantity-setter can always gain by turning into a price-setter. An intuitive explanation of this phenomenon can be given in the following terms. 
Consider for instance the inequality $\circledR^{\circledR a p}>\circledR^{p p}$, where $\circledR^{\circledR q p}$ is obtained by evenly splitting cartel pro.ts, so that the individual collusive pro..ts used to compute the two discount factors are the same. It is known that $1 / \mathrm{I}^{\mathrm{N}}$ is higher than the Bertrand-Nash equilibrium pro.t (Singh and Vives [16]), and it can be easily checked that the deviation pro..ts in the symmetric B ertrand setting are higher than the corresponding deviation pro..ts in the mixed case where the cheating ..rm is a quantity-setter while the cheated one is a price-setter. The overall exect yielding the above inequality is due to the fact that the $\mathrm{N}$ ash threat prevails over the incentive to defect, and discount factors turn out to be ordered the same as the punishment payoxs.

M oreover, recalling the conclusion reached by Singh and Vives [16] concerning the non-cooperative choice of the variable in the one-shot market game, the above analysis leads to the following corollary:

Corollary 1 When ..rms non-cooperatively select the market variable in order to stabilize collusion, they choose to act in the opposite strategy space as compared to that they would non-cooperatively select to maximize single period pro..ts.

Since ..rms are playing a repeated game on the market, where they are trying to collude in a sustainable way, one can imagine that, in order to achieve the Pareto-superior outcomeassociated with collusion in quantities, ...rms must repeat as well the interaction in the upstream stage in..nitely many times, building thus a meta-repeated game whose payous are the critical discount factors displayed in matrix 1 . The outcome is summarized in

Proposition 2 Firms can el ciently sustain collusion in quantities if their individual meta-discount factor is above the critical threshold(s) arising from the repetition of the constituent meta-game in..nitely many times.

Proof. The collusive payox corresponds to $\mathbb{\circledR}^{q q}$, the non-cooperative one to $\AA^{\circledR p p}$;

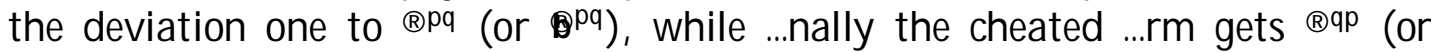
(ap). The critical thresholds of the meta-discount factor associated with the meta-repeated game are:

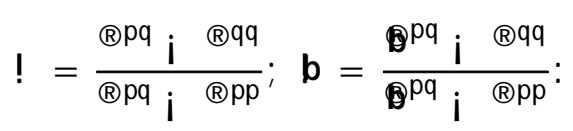

For collusion to be sustainable in the meta-repeated game, the individual meta-discount factors of players (which coincide in the meta-game) must satisfy either the following inequality:

$$
!_{i}>!=\frac{2\left(1+{ }^{\circ}\right)^{2}\left(8 i 8^{\circ}+{ }^{\circ} 2\right)\left({ }^{\circ 3}+6^{\circ 2} i \quad 8\right)}{\left(8+8^{\circ}+{ }^{\circ 2}\right)\left(2^{\circ 5} i 9^{\circ}{ }_{i} 2^{\circ 3}+24^{\circ 2} i 16\right)}
$$

or the alternative 


$$
!_{i}>b=\frac{2\left(1+{ }^{\circ}\right)^{2}\left(8 ; 8^{\circ}+{ }^{\circ}\right)}{\left(8+8^{\circ}+{ }^{\circ}\right)\left(6 i 5^{\circ}\right)}
$$

where ! 2 [1;0:808] and $\mathbf{b} 2$ [1=3;0:336]; provided that ${ }^{\circ} 2$ [0:; 0:73]:

A last remark can be put forward. The dixerence between ! and $\mathbf{b}$ is decreasing and strictly concave in ${ }^{\circ}$, for all ${ }^{\circ} 2$ [0; 0:73]; so that it appears that rule (7) yields higher stability, in that it yields a threshold which is considerably lower than that obtained when cartel pro.ts are evenly distributed across ..rms. Hence, when ..rms aim at stabilizing collusion over time, they are better ox resorting to rule (7), if a side payment is possible.

\section{Two eggs in one basket}

The possibility that ..rms select both the variable and the behavior, cooperative or non-cooperative, at the same time, remains to be investigated. From Singh and $V$ ives' analysis, it emerges that under non-cooperative behavior the quantitysetting behavior dominates the price-setting behavior, while from the preceding section one obtains that the non-cooperative choice of the variable in which ..rms can collude leads to a pricesetting behavior. As a consequence, I can construct a single-stage reduced form game where ..rms, in choosing the variable to be set, also choose which kind of behavior they want to assume. This is done in matrix 2, where the choice of price implies a collusive attitude, while the choice of quantity implies a non-cooperative attitude.

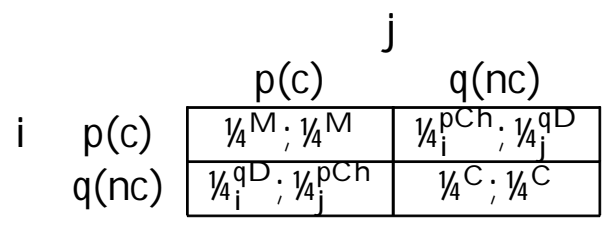

Matrix 2

Provided the price game is completely symmetric, $1 / 4^{M}=1 \mathrm{M}=2$ : The CournotNash equilibrium pro..t is $1 / 4=1=\left(2+{ }^{\circ}\right)^{2}$; while the pro..ts appearing in the asymmetric cases where one ..rm sets the optimal cartel price and the other deviates along her Cournot reaction function are de..ned in (9) and (10) above. The payoxs can be ordered as follows: $1 / 4 \mathrm{D}>1 / 4^{\mathrm{M}}>1 / 4>1 / \mathrm{pCh}^{\mathrm{C}}$ : Hence, I can claim: 
Proposition 3 In the game where .rms non-cooperatively and simultaneously choose both the market variable and mode of competitive behavior, the prisoners' dilemma which arises leads them to set quantities and play non-cooperatively.

The outcome is thus described by a Cournot-N ash equilibrium, $(q(n c), q(n c))$. A gain, ..rms can only improve on the non-cooperative result if they are su $ф$ ciently patient. The calculations needed to compute the critical threshold of the discount factor are straightforward. Proposition 3 shows that Singh and Vives' conclusion is robust to the introduction of the possibility that ..rms choose both strategic variables and modes of play.

\section{Conclusions}

If ..rms are able to establish which strategic variable is preferable in the market stage, why shouldn't they be able to do it in trying to sustain collusion? The answer to this question has shown that the remedy to the Pareto-ined ciency axecting the one-shot game, namely, the repetition in..nitely many times of the constituent game, reproduces the same dilemma when the strategic variable must be decided upon in order to obtain a stable cartel. A prisoners' dilemma also arises when ..rms are required to choose simultaneously whether to set prices or quantities and whether to behave cooperatively or non-cooperatively.

The foregoing analysis has also shown that ..rms exhibit opposite preferences to the market variable to be set, depending on whether they aim at maximizing single-period pro..ts (choosing to be quantity-setters in the one-shot market game) or cartel stability (choosing to be price-setters in the one-shot upstream stage). The outcome of the last game examined above leads one to conclude that the former attitude prevails upon the latter, if ..rms proceed to choose in a noncooperative way. 


\section{R eferences}

[1] D. A breu, Extremal Equilibria of Oligopolistic Supergames, J . E con. Theory 39 (1986), 191-225.

[2] M. Boyer and M. Moreaux, On Stackelberg Equilibria with Dixerentiated Products: The Critical R ole of the Strategy Space, J. Ind. E con. 36 (1987), 217-230.

[3] L. Cheng, Comparing Bertrand and Cournot Equilibria: A Geometric A pproach, RAND J . Econ., 16 (1985), 146-152.

[4] C. Davidson and R. Deneckere, Long-Run Competition in Capacity, ShortRun Competition in Price, and the Cournot Model, RAND J. Econ., 17 (1986), 404-415.

[5] R. Deneckere, Duopoly Supergames with Product Dixerentiation, Econ. Letters, 11 (1983), 37-42.

[6] V. Denicolò and L. Lambertini, On the Endogenous Choice of the Type of Competition in a Dixerentiated Duopoly, mimeo, Dipartimento di Scienze Economiche, Università degli Studi di Bologna, 1995.

[7] J.W. Friedman, A Non-Cooperative Equilibrium for Supergames, Rev. Econ. Stud., 28 (1971), 1-12.

[8] J. Hamilton and S. Slutsky, Endogenous Timing in Duopoly Games: Stackelberg or Cournot Equilibria, Games Econ. Behav., 2 (1990), 29-47.

[9] D. K reps and J. Scheinkman, Quantity Precommitment and Bertrand Competition Y ield Cournot Outcomes, B ell J . Econ., 14 (1983), 326-337.

[10] V.E. Lambson, Optimal Penal Codes in Price-Setting Supergames with Capacity Constraints, Rev. E con. Stud., 54 (1987), 385-397.

[11] R. Levitan and M. Shubik, Price Duopoly and Capacity Constraints, Int. Econ. Rev., 13 (1972), 111-123.

[12] D. Majerus, Price vs Quantity Competition in Oligopoly Supergames, Econ. Letters, 27 (1988), 293-297.

[13] K. Okuguchi, Equilibrium Prices in the Bertrand and Cournot Oligopolies, J. E con. Theory, 42 (1987), 128-139.

[14] M. Osborne and C. Pitchik, Price Competition in a Capacity-Constrained Duopoly, J. Econ. Theory, 38 (1986), 238-260.

[15] R. R othschild, On the Sustainability of Collusion in Dixerentiated Duopolies, Econ. Letters, 40 (1992), 33-37.

[16] N. Singh and X. Vives, Price and Quantity Competition in a Dixerentiated Duopoly, RAND J. Econ., 15 (1984), 546-554.

[17] X. Vives, E $₫$ ciency of Bertrand and Cournot Equilibria with Product Differentiation, J. Econ. Theory, 36 (1985), 166-175. 